\title{
Identification of Broad-Spectrum Dengue/Zika Virus Replication Inhibitors by Functionalization of Quinoline and 2,6-Diaminopurine Scaffolds
}

\author{
Suzanne J. F. Kaptein, ${ }^{[a]}$ Paolo Vincetti, ${ }^{[b]}$ Emmanuele Crespan, ${ }_{,}^{[c]}$ Jorge I. Armijos Rivera, ${ }^{[c]}$ \\ Gabriele Costantino, ${ }^{[b]}$ Giovanni Maga, ${ }^{[c]}$ Johan Neyts, ${ }^{[a]}$ and Marco Radi ${ }^{* b]}$
}

\begin{abstract}
Social and demographic changes across the world over the past 50 years have resulted in significant outbreaks of arboviruses such as dengue virus (DENV) and Zika virus (ZIKV). Despite the increased threat of infection, no approved drugs or fully protective vaccines are available to counteract the spread of DENV and ZIKV. The development of "broad-spectrum" antivirals (BSAs) that target common components of multiple viruses can be a more effective strategy to limit the rapid emergence of viral pathogens than the classic "one-bug/one-drug" approach. Starting from previously identified multitarget DENV inhibitors, herein we report the identification of novel 2,6-diaminopurine derivatives that are able to block the replication of both Zika virus and all serotypes of dengue virus (DENV 1-4) in infected cells.
\end{abstract}

Infectious diseases are still a major public health threat. Although a number of vaccines and antiviral drugs have been developed in the last century, the vast majority of infectious diseases (i.e., more than 200) caused by viruses belonging to different families are still untreatable. ${ }^{[1]}$ In addition, increased globalization and climate changes have led to an expansion in the worldwide spread of (sub)tropical viruses; as a result, these viruses are no longer confined to geographically limited risk areas. In the case of mosquito-borne viruses, insecticide resistance, poor sanitation, unplanned urbanization, and inadequate health services have also contributed to the endemicity of arboviruses in many regions of the world. Of these, dengue virus (DENV) and Zika virus (ZIKV) (genus Flavivirus), which are spread by mosquitos of the Aedes spp., are endemic in Asia, Africa, and Latin America, but multiple outbreaks have also recently occurred in Europe as a result of the spreading urge of the vectors. ${ }^{[2]}$ Current estimates indicate about $300-500$ million

[a] Dr. S. J. F. Kaptein, Prof. J. Neyts

Department of Microbiology and Immunology, Rega Institute for Medical

Research, Laboratory of Virology and Chemotherapy, KU Leuven, B-3000 Leuven (Belgium)

[b] Dr. P. Vincetti, Prof. G. Costantino, Prof. M. Radi

Dipartimento di Scienze degli Alimenti e del Farmaco, Università degli Studi di Parma, Viale delle Scienze, 27/A, 43124 Parma (Italy) E-mail:marco.radi@unipr.it

[c] Dr. E. Crespan, Dr. J. I. A. Rivera, Dr. G. Maga

National Research Council, Institute of Molecular Genetics IGM-CNR, Via Abbiategrasso 207, 27100 Pavia (Italy)

$\square$ Supporting information and the ORCID identification number(s) for the

(iD)

author(s) of this article can be found under:

https://doi.org/10.1002/cmdc.201800178.
DENV infections each year. Although the mortality rate of many flavivirus infections is relatively low (roughly $2.5 \%$ ), these infections can cause severe disease, such as microcephaly in fetuses and Guillain-Barré syndrome in adults that are caused by the host's immune response to the neurotropic $Z \mathrm{ZIKV}_{1}^{[3]}$ or hemorrhagic fever or shock in the case of the non-neurotropic DENV. ${ }^{[4]}$ Recent studies also found high loads of flavivirus RNA (DENV, ZIKV) in breast milk and saliva, suggesting that these vertical and sexual transmission routes can also contribute to the increased spreading of these viruses. Despite such potential threat, no approved drugs or fully protective vaccines are available to counteract the spread of DENV and ZIKV. The only approved tetravalent DENV vaccine (CYD-TDV) did not meet the expectations by exhibiting $60 \%$ efficacy in symptomatic dengue and only limited efficacy in yet unexposed dengue recipients, who may thus develop an aggravated form of the disease. ${ }^{[5]}$ On the ZIKV front, Sanofi Pasteur recently halted the development of a Zika vaccine, ${ }^{[6]}$ leaving a few open questions on the real value of flavivirus vaccines. In contrast, a small-molecule drug delivered early or even taken prophylactically may have a significant impact on the prevention and progression of these arthropod-borne diseases by lowering the viral load in the blood and decreasing the number of carrier mosquitoes that become infected after feeding on a viraemic patient, thus lowering transmission.

Among the possible antiviral approaches, developing smallmolecule "broad-spectrum" antivirals (BSAs) that target common mechanisms of action of multiple viruses, can be a more effective strategy to limit the rapid rise of emerging viral pathogens than the classic "one-bug/one-drug" approach. BSAs may allow the immediate initiation of a prophylactic or therapeutic treatment in an outbreak setting of unknown, yet suspected, etiology for which a specific antiviral drug is still unavailable. In addition, BSAs may offer better treatment options for multi-species co-infections, which is one of the greatest challenges to global health, creating confusion and delay in diagnosis and treatment, and leading to additive or synergistic morbidities. ${ }^{[7]}$ Co-infection with arboviruses (e.g., DENV, ZIKV, chikungunya virus) co-circulating within the same vector creates significant difficulties in diagnosing, controlling, and treating infected individuals and leads to complicated immune responses toward other viruses or host proteins (Guillain-Barré syndrome). ${ }^{[8]}$

As part of our continuous efforts to find innovative antiviral candidates, ${ }^{[9]}$ we recently reported the identification of multitarget compounds that are able to inhibit DENV replication by 
targeting both host kinases c-Src/Fyn and an allosteric site on the thumb of viral NS5 required to form the functional NS5NS3 replication complex. ${ }^{[10]}$ Herein we describe the further optimization of these DENV inhibitors into compounds that block the replication of multiple flaviviruses (namely DENV and ZIKV). This may represent an effective and cheap strategy for controlling the spread of both viruses and related co-infections by a single molecule.

The urgency of finding effective countermeasures to the increasing flavivirus spreading is testified by the fact that most compounds so far tested in dengue clinical trials are repurposed molecules initially developed for other indications. ${ }^{[18]}$ Despite their in vivo safety profile, these repurposed molecules were not suitable for application as dengue therapeutics. However, they may provide useful indications on which scaffolds could be further pursued in lead optimization studies (e.g., purine and quinoline scaffolds). At the same time, ex novo targeted approaches against host or viral proteins have been pursued to develop new drug candidates with broad-spectrum activity against flaviviruses. ${ }^{[19]}$ Among the different approaches, the NS5 polymerase still represents the most promising and exploited target for the development of broad-spectrum antiflaviviral agents. This protein is in fact highly conserved among flaviviruses, lacks a eukaryotic homologue, and is effectively inhibited by nucleoside derivatives (chain terminator antivirals; NIs), whose main drawback for clinical application is off-target toxicity and low phosphorylation in DENV-infected patients by host kinases. A few DENV non-nucleoside inhibitors (NNIs) targeting an allosteric pocket close to the priming loop ( $\mathrm{N}$ pocket) have also been discovered. However, because of their toxicity in an animal model, high predisposition to resistance selection, ${ }^{[20]}$ and the fact that the same priming loop adopts a closer conformation in ZIKV NS5 (resulting in a smaller $\mathrm{N}$ pocket that is unfit to bind these DENV NNIs), ${ }^{[21]}$ they may not represent the most promising anti-flavivirus drug candidates. NS5 polymerase also presents an allosteric pocket (cavity B) that binds NS3 to form the functional replication complex. This pocket is highly conserved among flaviviruses and represents an underexplored site to develop resistance-robust non-nucleoside anti-flaviviral agents. ${ }^{[22]}$

Previously, we reported the discovery of the first multitarget inhibitors (i.e., 1 and 2) that inhibited DENV replication at lowmicromolar concentrations (Figure 1) by interfering with the NS3-NS5 interaction. ${ }^{[10]}$ These inhibitors were rationally designed by repurposing Src kinase scaffolds to bind NS5 cavity $B$, thus aiming for the contemporary inhibition of Src/Fyn kinases and NS3-NS5 interaction, which are both involved in DENV replication. ${ }^{[23]}$ Compared with ribavirin $\left(\mathrm{EC}_{50}=42.0 \mu \mathrm{m}\right.$; $\mathrm{SI}>10$ ), compounds 1 and 2 showed a promising antiviral profile with $\mathrm{EC}_{50}$ values of 5.3 and $7.4 \mu \mathrm{M}$ and selectivity indexes $\left(\mathrm{SI}=\mathrm{CC}_{50} / \mathrm{EC}_{50}\right)$ of 168 and $>175$, respectively. As can be expected from the homology between DENV NS5 and ZIKV NS5, a number of DENV NS5 inhibitors (e.g., BCX4430, 7DMA, 2'CMA, NITD008; Figure 1) were also found to inhibit ZIKV replication at similar concentrations. ${ }^{[19]}$ For this reason, we decided to test our multitarget inhibitors $\mathbf{1}$ and $\mathbf{2}$ as ZIKV replication inhibitors. To our surprise, both compounds were completely inactive against ZIKV (Table 1). However, considering 1) the high homology between DENV and ZIKV NS5, 2) the presence of a highly conserved and functionally relevant allosteric site (cavity B) within flavivirus NS5, and 3) the privileged structure of quinoline and purine scaffolds among flavivirus inhibitors, we decided to further explore derivatives within these two classes.

Focused synthetic modifications of our previously reported quinolines/purines were herein conducted to better understand their structural requirements to properly interact with cavity B of both DENV and ZIKV and inhibit their replication using a single molecule. Quinoline derivative $\mathbf{3}$ is a bosutinib

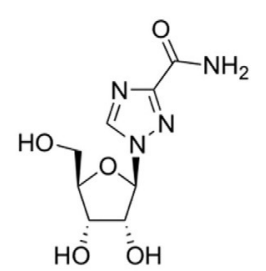

Ribavirin $\left(\mathrm{EC}_{50}=42.0 \mu \mathrm{M}\right)^{[10]}$

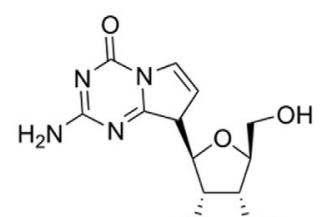

$\mathrm{HO}$

ZX-2401 $\left(\mathrm{EC}_{50}=35.4 \mu \mathrm{M}\right)^{[11]}$

$$
\begin{aligned}
& \text { REPURPOSED } \\
& \text { ANTIVIRALS }
\end{aligned}
$$

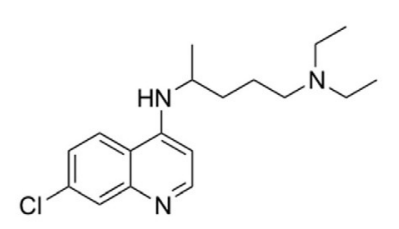

Chloroquine $\left(\mathrm{EC}_{50}=25 \mu \mathrm{M}\right)^{[12]}$<smiles>CCN(CC)Cc1cc(Nc2ccnc3cc(Cl)ccc23)ccc1O</smiles>

Amodiaquine $\left(\mathrm{EC}_{50}=1.1 \mu \mathrm{M}\right)^{[13]}$

REPURPOSED

ANTIMALARIALS<smiles>Nc1ncnc2c(C3OC(CO)[C@H](O)C3O)c[nH]c12</smiles>

$\mathrm{BCX} 4430\left(\mathrm{EC}_{50}=32.8 \mu \mathrm{M}\right)^{[14]}$<smiles>[X]c1c(N)ncnc1[C@@H]1O[C@H](CO)[C@@H](O)[C@]1([R])O</smiles>

7DMA; $X=C, R=M e\left(E C_{50}=15.0 \mu \mathrm{M}\right)^{[15]}$ 2'CMA; $X=N, R=M e\left(E C_{50}=2.4 \mu M\right)^{[16]}$ NITD008; $X=C, R=\left\{=\left(E C_{50}=0.6 \mu M\right)^{[17]}\right.$

BROAD-SPECTRUM NS5 INHIBITORS<smiles>CNc1nc(Nc2cccc(O)c2)c2nc[nH]c2n1</smiles>

$1\left(\mathrm{EC}_{50}=5.3 \mu \mathrm{M}\right)^{[10]}$

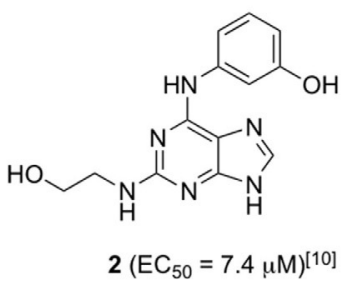

MULTITARGET DENV INHIBITORS

Figure 1. Selected flavivirus inhibitors and their in vitro inhibition (expressed as $\mathrm{EC}_{50}$ values) of DENV-2 replication. 


\begin{tabular}{|c|c|c|c|c|}
\hline \multirow[t]{2}{*}{ Compd } & \multicolumn{2}{|c|}{ DENV-2 } & \multicolumn{2}{|c|}{ ZIKV } \\
\hline & $\mathrm{EC}_{50}[\mu \mathrm{M}]^{[\mathrm{a}]}$ & $\mathrm{CC}_{50}[\mu \mathrm{M}]^{[\mathrm{b}]}$ & $\mathrm{EC}_{50}[\mu \mathrm{M}]^{[\mathrm{a}]}$ & $C C_{50}[\mu \mathrm{M}]^{[\mathrm{b}]}$ \\
\hline 3 & $N A^{[c]}$ & 19 & $N D^{[d]}$ & ND \\
\hline 4 & $>140$ & $>140$ & ND & ND \\
\hline $9 \mathrm{a}$ & $<1.9$ & $<1.9$ & ND & ND \\
\hline $9 b$ & $<1.7$ & $<1.7$ & ND & ND \\
\hline $9 c$ & $<1.6$ & $<1.6$ & ND & ND \\
\hline $9 d$ & 8.8 & 44.4 & ND & ND \\
\hline 9 e & NA & 29.3 & ND & ND \\
\hline $9 f$ & NA & 2.0 & ND & ND \\
\hline 1 & $2.4 \pm 0.9^{[\mathrm{e}]}$ & $168 \pm 38$ & $>100$ & $>100$ \\
\hline 2 & $7.4 \pm 0.7$ & $>175$ & $>100$ & $>100$ \\
\hline $12 \mathrm{a}$ & $10.0 \pm 1.9$ & $69.4 \pm 12.5$ & $16.7 \pm 10.2$ & $>124 \pm 25$ \\
\hline $12 \mathrm{~b}$ & $2.8 \pm 1.0$ & $14.6 \pm 7.7$ & $12.2 \pm 6.4$ & $>122$ \\
\hline $12 \mathrm{c}$ & 12.6 & 26.3 & ND & ND \\
\hline $12 d$ & 3.1 & 4.5 & ND & ND \\
\hline $12 \mathrm{e}$ & 4.9 & 19.3 & ND & ND \\
\hline $12 f$ & 40.6 & 122 & ND & ND \\
\hline $\mathrm{RBV}^{[\mathrm{ff}]}$ & $11.9 \pm 4.0$ & $>409$ & ND & ND \\
\hline $7 \mathrm{DMA}^{[\mathrm{g}]}$ & ND & ND & $5.6 \pm 11$ & $>357$ \\
\hline
\end{tabular}

[a] $\mathrm{EC}_{50}$ values were generated using the virus-yield reduction assay. [b] $\mathrm{CC}_{50}$ values were assessed by the MTS method. [c] NA= not active. [d] $N D=$ not determined. [e] Values are the mean $\pm S D$ of at least three independent experiments. [f] Ribavirin. [g] 7-Deaza-2'-C-methyladenosine.

analogue that was proposed to interact with DENV cavity B and, at the same time, inhibit Src/Fyn kinase activity. We found this compound quite cytotoxic and unable to inhibit DENV replication at concentrations below its $\mathrm{CC}_{50}$ value. ${ }^{[10]}$ Repurposing of kinase inhibitors as antivirals is quite risky due to their broad effect on the kinome and their anti-metabolic/cytotoxic profile. In addition, although dasatinib and saracatinib were earlier proposed to impede DENV replication via inhibition of Src/Fyn, we suggested that the inhibition of Src/Fyn alone may not result in an antiviral effect. ${ }^{[10]}$ Consequently, we decided to convert $\mathbf{3}$ into a derivative unable to interact with the Src/Fyn hinge domain by masking the endocyclic quinoline nitrogen atom that acts as a hydrogen bond acceptor in the interaction with the kinase hinge domain. Treatment of $\mathbf{3}$ with methyl iodide and sodium hydride generated 1-methyl derivative 4 in $50 \%$ yield (Scheme 1). At the same time, we also prepared a series of analogues of compound 3 by installing different moieties at position $\mathrm{C} 4$ of the quinoline core. Starting from 3-methoxyaniline (5), a one-pot two-step microwave-assisted Gould-Jacobs cyclization allowed us to easily obtain the key intermediate 7, which was then chlorinated and finally submitted to nucleophilic substitution with various amines to give final compounds $\mathbf{9} \mathbf{a}-\mathbf{f}$ (Scheme 2).<smiles></smiles>

Scheme 1. Reagents and conditions: a) Mel, NaH, THF, RT, 68 h.

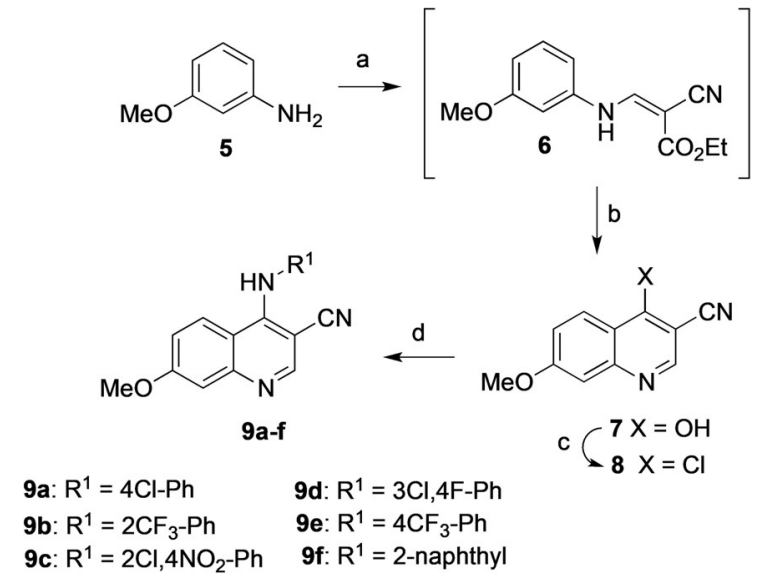

Scheme 2. Reagents and conditions: a) ethyl 2-cyano-3-ethoxyacrylate, neat, $\mu \mathrm{W} 120^{\circ} \mathrm{C}, 5 \mathrm{~min}$; b) $\mathrm{Ph}_{2} \mathrm{O}, \mu \mathrm{W} 230^{\circ} \mathrm{C}, 5-7 \mathrm{~min}$; c) $\mathrm{POCl}_{3}$, reflux, $2 \mathrm{~h}$; d) $\mathrm{R}^{1} \mathrm{NH}_{2}, \mathrm{DMF}, \mathrm{NaH}, 2 \mathrm{~h}$, reflux.

Previous SAR data on our purine series showed that the most promising anti-DENV compounds possess a 3-aminophenol substituent at position C6. For this reason, in the present work we kept this moiety fixed at position $\mathrm{C} 6$ and focused on the functionalization of position C2: starting from commercially available 2,6-dichloropurine (10), regioselective C4 nucleophilic substitution with 3 -aminophenol led to key intermediate 11, which was submitted to a C2 nucleophilic substitution with primary or secondary amines to give final compounds $12 \mathrm{a}-\mathrm{f}$ (Scheme 3). As suggested in our previous study, position C2 of active purines may tolerate different functional groups. ${ }^{[10]}$<smiles>[R10][Y10](C)=Nc1nc(Nc2cccc(O)c2)c2nc[nH]c2n1</smiles>

$\begin{array}{ll}\text { 12a: } R^{1}=\text { phenoxyethyl } & 12 d: R^{1}=3,5-M e-P h \\ 12 b: R^{1}=4-p h e n y l b e n z y l & 12 e: R^{1}=2,4-M e-P h\end{array}$ $\begin{array}{ll}\text { 12b: } R^{1}=4-\text { phenylbenzyl } & 12 e: R^{1}=2,4-M e-P h \\ \text { 12c: } R^{1}=P h & 12 f: R^{1} \mathrm{NH}=\text { morpholine }\end{array}$

Scheme 3. Reagents and conditions: a) 3-aminophenol, $n \mathrm{BuOH}, \mu \mathrm{W} 80^{\circ} \mathrm{C}$, $10 \mathrm{~min}$; b) $\mathrm{R}^{1} \mathrm{NH}_{2}, \mathrm{TFA}, \mu \mathrm{W} 170^{\circ} \mathrm{C}, 10 \mathrm{~min}$, then $150^{\circ} \mathrm{C}, 10 \mathrm{~min}$.

Docking studies on DENV cavity B also suggested that the introduction of an hydrophobic moiety in $\mathrm{C} 2$ of the purine scaffold may allow to better fill the hydrophobic cavities surrounding the key residue Lys330. Compounds 12 a-e were thus prepared to better understand the effect of additional hydrophobic interactions around Lys330, while compound $12 \mathrm{f}$ was prepared as an analogue of compound $\mathbf{2}$ to evaluate the requirement for a hydrogen bond donor at position C2 for biological activity. All synthesized compounds were biologically evaluated for their ability to inhibit DENV serotype 2 (DENV-2) replication using a virus yield reduction assay. Results are listed in Table 1 in comparison with previously reported hits $\mathbf{1 - 3}$, rib- 
avirin (RBV) and 7-deaza-2'-C-methyladenosine (7DMA), ${ }^{[24]}$ which were included as reference compounds. Testing of quinoline derivatives showed that $\mathrm{N} 1$ methylation (compound 4) decreased cytotoxicity, although it was still incapable of inhibiting DENV replication. Among C4-substituted quinolines $\mathbf{9} \mathbf{a}-\mathbf{f}$, only compound $\mathbf{9} \mathbf{d}$ displayed antiviral activity, albeit with a low selectivity index $(S I=5)$. Other quinolines were either cytotoxic or inactive. As anticipated, the most interesting data were obtained from the purine series. In contrast to hit $\mathbf{2}$, the 2-morpholino derivative $\mathbf{1 2} \mathbf{f}$ did not exhibit a clear antiviral effect, suggesting that the $\mathrm{NH}$ hydrogen bond donor moiety at position C2 is needed for antiviral activity. Regarding C2 hydrophobicextended compounds $12 \mathrm{a}-\mathrm{e}:$ 1) 2-aniline derivatives $12 \mathrm{c}-\mathrm{e}$ showed sub- to low-micromolar activity against DENV-2, but were also quite cytotoxic; 2) compounds $12 \mathrm{a}$ and $12 \mathrm{~b}$ showed the most promising results by inhibiting DENV-2 replication at low-micromolar concentrations and by displaying a more favorable cytotoxicity profile. More importantly, $12 \mathrm{a}$ and $12 \mathrm{~b}$ also proved to inhibit ZIKV replication with similar $\mathrm{EC}_{50}$ values, whereas their progenitors 1 and $\mathbf{2}$ were completely inactive against ZIKV (Table 1). Compounds $\mathbf{1 2} \mathbf{a}, \mathbf{b}$ were also tested in a small panel of selected kinases that were reported to play a role in the replication of DENV/ZIKV (Fyn, Abl, Src) and other viruses (CDK9, CDK4). As shown in Table 2, selected kinases retained much of their activity when treated with compounds $12 \mathbf{a}, \mathbf{b}$ (with the exception of $12 \mathrm{a}$ against $\mathrm{Src}$ ) at a fixed concentration (corresponding to its lowest $\mathrm{CC}_{50}$ value), while they were almost completely inhibited by the reference compounds flavopyridol and dasatinib. In addition, considering that similar purine derivatives proved active against serine/ threonine protein kinases (e.g., BRAF), ${ }^{[25]}$ we also tested compounds $12 \mathbf{a}, \mathbf{b}$ against a few representative serine/threonine protein kinases (DYRK1a, GSK3 $\beta$, CHK1, and LRRK2), but they were completely inactive when tested at their $\mathrm{CC}_{50}$ concentration (data not shown). It is therefore reasonable to assume that our new compounds $(\mathbf{1 2} \mathbf{a}, \mathbf{b})$ may inhibit flavivirus replication by establishing an optimal interaction with NS5 cavity B of both DENV and ZIKV, while progenitors 1 and $\mathbf{2}$ establish profitable interactions with DENV cavity $B$ only. Considering the large homology of NS5 cavity B of different flaviviruses, we evaluated the effect of $12 \mathrm{a}$ and $\mathbf{1 2} \mathrm{b}$ in inhibiting the replication of other DENV serotypes. As expected, both compounds inhibited the replication of DENV-1, -3 , and -4 with $\mathrm{EC}_{50}$ values
Table 3. Dengue inhibitory activity and cytotoxicity of $12 \mathrm{a}, \mathrm{b}$ against serotypes 1,3 , and 4 .

\begin{tabular}{lcccccc} 
Compd & \multicolumn{2}{c}{ DENV-1 } & \multicolumn{2}{c}{ DENV-3 } & \multicolumn{2}{c}{ DENV-4 } \\
& $\mathrm{EC}_{50}[\mu \mathrm{M}]^{[\mathrm{a}]}$ & $\mathrm{CC}_{50}[\mu \mathrm{M}]^{[\mathrm{b}]}$ & $\mathrm{EC}_{50}[\mu \mathrm{M}]^{[\mathrm{a}]}$ & $\mathrm{CC}_{50}[\mu \mathrm{M}]^{[\mathrm{b}]}$ & $\mathrm{EC}_{50}[\mu \mathrm{M}]^{[\mathrm{a}]}$ & $\mathrm{CC}_{50}[\mu \mathrm{M}]^{[\mathrm{b}]}$ \\
\hline $12 \mathrm{a}$ & 14.0 & 60.5 & 12.9 & 60.5 & 11.6 & 60.5 \\
$12 \mathrm{~b}$ & 1.38 & 20.5 & 1.93 & 20.5 & 2.19 & 20.5 \\
$\mathrm{RBV}^{[\mathrm{c}]}$ & 143 & 410 & 138 & 410 & 68 & 410
\end{tabular}

[a] $\mathrm{EC}_{50}$ values were generated using the virus-yield reduction assay. [b] $\mathrm{CC}_{50}$ values were assessed by MTS method. [c] Ribavirin.

similar to those found for DENV-2, whereas the broad-spectrum reference drug ribavirin shows only a very moderate antiviral effect against DENV serotypes 1, 3, and 4 (Table 3).

To understand why compounds $12 \mathrm{a}$ and $12 \mathrm{~b}$ were active against DENV and ZIKV while progenitors 1 and $\mathbf{2}$ were only active against DENV, we conducted docking experiments on NS5 cavity B of both viruses. During the past year, four different research groups reported almost simultaneously on the crystal structure of ZIKV NS5 polymerase. ${ }^{[21,26-28]}$ Analysis of these structures revealed that cavity $B$ is highly conserved among DENV and ZIKV (RMSD range: $0.34-0.56 \AA$ ), with the structure reported by Zhao et al. ${ }^{[28]}$ showing the best global similarity (RMSD $=0.99 \AA$ ) with DENV NS5. This structure (PDB ID: 5UOC) was therefore selected for docking studies, which were conducted using AutoDock Vina. ${ }^{[29]}$ In agreement with the lack of activity against ZIKV replication, docking of compounds 1 and $\mathbf{2}$ did not show any cluster of molecules bound to cavity B among the top-ranked positions. In contrast, compounds $12 \mathrm{a}$ and $12 \mathrm{~b}$ showed profitable interactions and similar binding modes with both cavities, which is fully in line with the in vitro data on the inhibition of DENV and ZIKV replication (Figure 2).

In summary, exploration of the chemical space around two chemical scaffolds previously identified by us (quinoline and 2,6-diaminopurine) allowed conversion of the multitarget inhibitor of DENV replication and Src/Fyn kinases (1) into novel inhibitors (12a and $\mathbf{1 2} \mathrm{b}$ ) with broad-spectrum anti-flavivirus activity and no significant adverse effect on the activity of a mini-panel of host kinases. Although the pharmacological and antiviral profile is still unsuitable for evaluation in in vivo studies, compounds $12 \mathrm{a}$ and $\mathbf{1 2} \mathrm{b}$ can be regarded as among the few non-nucleoside, broad-spectrum flavivirus inhibitors re-

Table 2. Inhibitory effect of synthesized compounds against selected kinases.

\begin{tabular}{|c|c|c|c|c|c|c|}
\hline \multirow[t]{2}{*}{ Compound } & \multicolumn{6}{|c|}{ Residual enzymatic activity [\%] } \\
\hline & CDK9/cT1 & CDK9/cK & CDK4/cD1 & Fyn & Abl & Src \\
\hline $12 \mathrm{a} @ 60.5 \mu \mathrm{m}^{[\mathrm{a}]}$ & $76.4 \pm 10.2$ & $93.8 \pm 13.4$ & $70.1 \pm 9.5$ & $27.7 \pm 4.5$ & $62.8 \pm 7.4$ & $9.6 \pm 0.8$ \\
\hline $12 \mathrm{a} @ 5.0 \mu \mathrm{m}^{[\mathrm{b}]}$ & - & - & - & $45.0 \pm 6.9$ & $65.0 \pm 5.6$ & $59.0 \pm 9.4$ \\
\hline $12 \mathrm{~b} @ 20.5 \mu \mathrm{M}^{[\mathrm{a}]}$ & $90.2 \pm 11.5$ & $94.0 \pm 8.8$ & $66.0 \pm 7.2$ & $63.2 \pm 8.1$ & $57.7 \pm 6.2$ & $21.5 \pm 3.9$ \\
\hline $12 \mathrm{~b} @ 1.5 \mu \mathrm{M}^{[\mathrm{b}]}$ & - & - & - & $81.0 \pm 10.1$ & 100.0 & $91.0 \pm 12.8$ \\
\hline flavopyridol@ @ $0.1 \mu \mathrm{M}$ & $0.1 \pm 0.01$ & $0.1 \pm 0.01$ & $41.1 \pm 0.5$ & - & - & - \\
\hline dasatinib @ $0.5 \mu \mathrm{M}$ & - & - & - & $0.1 \pm 0.01$ & $0.1 \pm 0.01$ & $0.8 \pm 0.01$ \\
\hline
\end{tabular}

[a] Compound was tested at a fixed concentration corresponding to its lowest $\mathrm{CC}_{50}$ value. [b] Compound was tested at a fixed concentration corresponding to its lowest $\mathrm{EC}_{50}$ value. Values are the mean $\pm \mathrm{SD}$ of two independent experiments. 


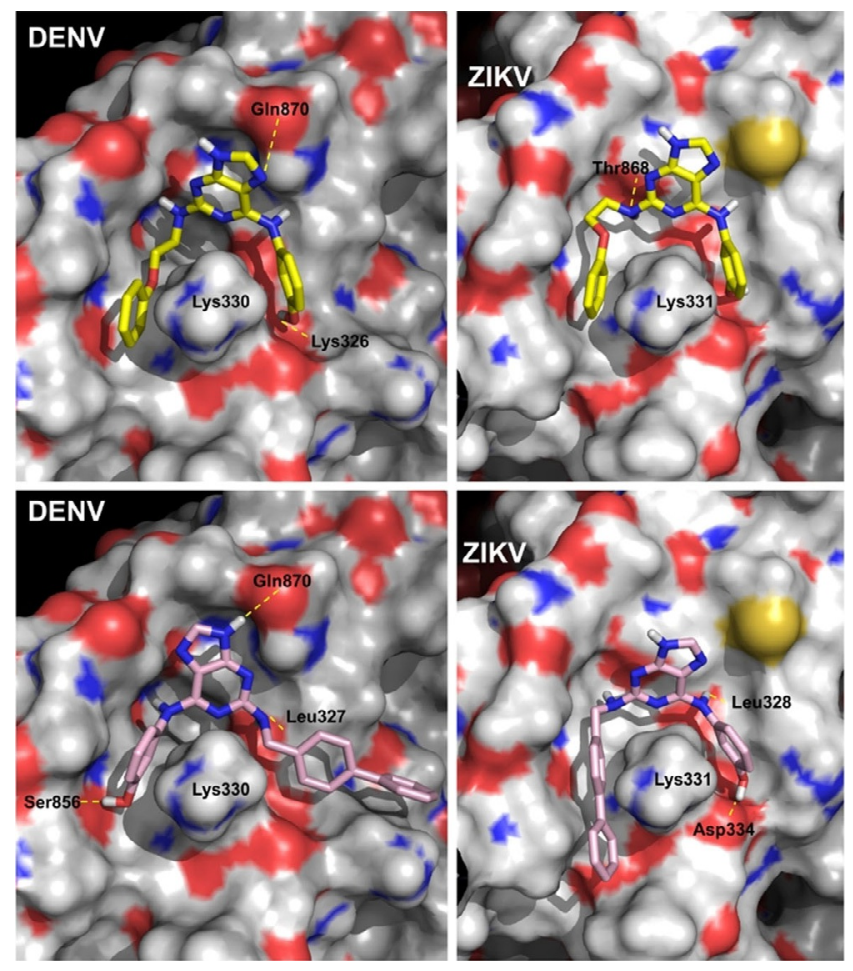

Figure 2. Binding mode of compounds $12 \mathrm{a}$ (yellow sticks) and $\mathbf{1 2} \mathbf{b}$ (pink sticks) within DENV cavity B (left) and ZIKV cavity B (right). Hydrogen bonds are depicted as yellow dotted lines. Images were generated by PyMOL. ${ }^{[30]}$

ported so far. ${ }^{[19]}$ Because these compounds are inexpensive to produce and easy to functionalize, they are a promising starting point for optimizing their pharmacological profile. Further studies in this direction will be reported in due course.

\section{Experimental Section}

Procedures for compound syntheses, docking studies, and biological evaluations are provided in the Supporting Information.

\section{Acknowledgements}

This work was supported by the University of Parma (M.R.). We thank Charlotte Vanderheydt, Caroline Collard, Ruben Pholien, and Grazia Larosa for excellent technical assistance.

\section{Conflict of interest}

The authors declare no conflict of interest.

Keywords: 2,6-diaminopurines - broad-spectrum antivirals co-infections $\cdot$ dengue $\cdot$ zika

[1] E. De Clercq, G. Li, Clin. Microbiol. Rev. 2016, 29, 695-747.

[2] S. C. Weaver, C. Charlier, N. Vasilakis, M. Lecuit, Annu. Rev. Med. 2018, 69, $395-408$.

[3] a) Štrafela, A. Vizjak, J. Mraz, J. Mlakar, J. Pižem, N. Tul, T. A. Županc, M. Popović, Arch. Pathol. Lab. Med. 2016, 141, 73-81; b) Q. Shao, S. Herrlin- ger, S. L. Yang, F. Lai, J. M. Moore, M. A. Brindley, J. F. Chen, Development 2016, 143, 4127-4136.

[4] M. Puccioni-Sohler, C. N. Soares, R. Papaiz-Alvarenga, M. J. Castro, L. C. Faria, J. M. Peralta, Neurology 2009, 73, 1413-1417.

[5] M. L. Robinson, A. P. Durbin, Curr. Opin. Infect. Dis. 2017, 30, 449-454.

[6] L. M. Jarvis, Chem. Eng. News 2017, 36, 10.

[7] R. B. Birger, R. D. Kouyos, T. Cohen, E. C. Griffiths, S. Huijben, M. J. Mina, V. Volkova, B. Grenfell, C. J. E. Metcalf, Trends Microbiol. 2015, 23, 537 544.

[8] H. A. Rothan, M. R. M. Bidokhti, S. N. Byrareddy, J. Autoimmun. 2018, 89, $11-20$.

[9] a) S. Tassini, L. Sun, K. Lanko, E. Crespan, E. Langron, F. Falchi, M. Kissova, J. I. Armijos-Rivera, L. Delang, C. Mirabelli, J. Neyts, M. Pieroni, A. Cavalli, G. Costantino, G. Maga, P. Vergani, P. Leyssen, M. Radi, J. Med. Chem. 2017, 60, 1400-1416; b) M. Radi, M. Pagano, L. Franchi, D. Castagnolo, S. Schenone, G. Casaluce, C. Zamperini, E. Dreassi, G. Maga, A. Samuele, E. Gonzalo, B. Clotet, J. A. Esté, M. Botta, ChemMedChem 2012, 7, 883 896 ; c) G. Maga, F. Falchi, M. Radi, L. Botta, G. Casaluce, M. Bernardini, H. Irannejad, F. Manetti, A. Garbelli, S. Zanoli, J. A. Esté, E. González, E. Zucca, S. Paolucci, F. Baldanti, J. De Rijck, Z. Debyser, M. Botta, ChemMedChem 2011, 6, 1371-1389; d) S. Freisz, G. Bec, M. Radi, P. Wolff, E. Crespan, L. Angeli, P. Dumas, G. Maga, M. Botta, E. Ennifar, Angew. Chem. Int. Ed. 2010, 49, 1805-1808; Angew. Chem. 2010, 122, 1849 1852.

[10] P. Vincetti, F. Caporuscio, S. Kaptein, A. Gioiello, V. Mancino, Y. Suzuki, N. Yamamoto, E. Crespan, A. Lossani, G. Maga, G. Rastelli, D. Castagnolo, J. Neyts, P. Leyssen, G. Costantino, M. Radi, J. Med. Chem. 2015, 58, 4964 4975.

[11] J. O. Ojwang, S. Ali, D. F. Smee, J. D. Morrey, C. D. Shimasaki, R. W. Sidwell, Antiviral Res. 2005, 68, 49-55.

[12] R. Delvecchio, L. M. Higa, P. Pezzuto, A. L. Valadão, P. P. Garcez, F. L. Monteiro, E. C. Loiola, A. A. Dias, F. J. Silva, M. T. Aliota, E. A. Caine, J. E. Osorio, M. Bellio, D. H. O'Connor, S. Rehen, R. S. de Aguiar, A. Savarino, L. Campanati, A. Tanuri, Viruses 2016, 8, 322.

[13] S. Boonyasuppayakorn, E. D. Reichert, M. Manzano, K. Nagarajan, R. Padmanabhan, Antiviral Res. 2014, 106, 125-134.

[14] T. K. Warren, J. Wells, R. G. Panchal, K. S. Stuthman, N. L. Garza, S. A. Van Tongeren, L. Dong, C. J. Retterer, B. P. Eaton, G. Pegoraro, S. Honnold, S. Bantia, P. Kotian, X. Chen, B. R. Taubenheim, L. S. Welch, D. M. Minning, Y. S. Babu, W. P. Sheridan, S. Bavari, Nature 2014, 508, 402-405.

[15] D. B. Olsen, A. B. Eldrup, L. Bartholomew, B. Bhat, M. R. Bosserman, A. Ceccacci, L. F. Colwell, J. F. Fay, O. A. Flores, K. L. Getty, J. A. Grobler, R. L. LaFemina, E. J. Markel, G. Migliaccio, M. Prhavc, M. W. Stahlhut, J. E. Tomassini, M. MacCoss, D. J. Hazuda, S. S. Carroll, Antimicrob. Agents Chemother. 2004, 48, 3944-3953.

[16] C. Y. Ng, F. Gu, W. Y. Phong, Y. L. Chen, S. P. Lim, A. Davidson, S. G. Vasudevan, Antiviral Res. 2007, 76, 222-231.

[17] Z. Yin, Y. L. Chen, W. Schul, Q. Y. Wang, F. Gu, J. Duraiswamy, R. R. Kondreddi, P. Niyomrattanakit, S. B. Lakshminarayana, A. Goh, H. Y. Xu, W. Liu, B. Liu, J. Y. Lim, C. Y. Ng, M. Qing, C. C. Lim, A. Yip, G. Wang, W. L. Chan, H. P. Tan, K. Lin, B. Zhang, G. Zou, K. A. Bernard, C. Garrett, K. Beltz, M. Dong, M. Weaver, H. He, A. Pichota, V. Dartois, T. H. Keller, P. Y. Shi, Proc. Natl. Acad. Sci. USA 2009, 106, $20435-20439$.

[18] a) J. G. H. Low, E. E. Ooi, S. G. Vasudevan, J. Infect. Dis. 2017, 215, S96S102; b) L. Botta, M. Rivara, V. Zuliani, M. Radi, Front. Biosci. 2018, 23, 997- 1019.

[19] V. Boldescu, M. A. M. Behnam, N. Vasilakis, C. D. Klein, Nat. Rev. Drug Discovery 2017, 16, 565-586.

[20] A. El Sahili, J. Lescar, Viruses 2017, 9, 91.

[21] A. S. Godoy, G. M. Lima, K. I. Oliveira, N. U. Torres, F. V. Maluf, R. V. Guido, G. Oliva, Nat. Commun. 2017, 8, 14764.

[22] P. Stephen, S. X. Lin, Chem. Biol. Drug Des. 2018, 91, $322-327$.

[23] a) J. J. H. Chu, P. L. Yang, Proc. Natl. Acad. Sci. USA 2007, 104, $3520-$ 3525 ; b) M. Wispelaere, A. J. LaCroix, P. L. Yang, J. Virol. 2013, 87, 7367 7381.

[24] J. Zmurko, R. E. Marques, D. Schols, E. Verbeken, S. J. F. Kaptein, J. Neyts, PLoS Negl. Trop. Dis. 2016, 10, e0004695.

[25] H. Park, Y. Jeong, S. Hong, Bioorg. Med. Chem. Lett. 2012, 22, $1027-$ 1030.

[26] A. K. Upadhyay, M. Cyr, K. Longenecker, R. Tripathi, C. Sun, D. J. Kempf, Acta Crystallogr. Sect. F 2017, 73, 116-122. 
[27] B. Wang, X. F. Tan, S. Thurmond, Z. M. Zhang, A. Lin, R. Hai, J. Song, Nat. Commun. 2017, 8, 14763.

[28] B. Zhao, G. Yi, F. Du, Y. C. Chuang, R. C. Vaughan, B. Sankaran, C. C. Kao, P. Li, Nat. Commun. 2017, 8, 14762.

[29] O. Trott, A. J. Olson, J. Comput. Chem. 2010, 31, 455-461.
[30] The PyMOL Molecular Graphics System, version 1.6-a, Schrödinger LLC, New York, NY (USA), 2013.

Manuscript received: March 19, 2018

Revised manuscript received: May 4, 2018

Accepted manuscript online: May 9, 2018

Version of record online: June 1, 2018 